\title{
Fatores de risco ambientais para o câncer gástrico: a visão do toxicologista
}

\author{
Environmental risk factors for gastric cancer: \\ the toxicologist's standpoint
}

Maria Regina Gomes-Carneiro 1

Luís Fel ipe Ribeiro-Pinto 1

Francisco José Roma Paumgartten 1

1 Laboratório de Toxicologia Ambiental, Departamento de Ciências Biológicas, Escola Nacional de Saúde Pública, Fundação Oswaldo Cruz. Av. Leopoldo Bulhões 1480, Rio de Janeiro, RJ 21041-210, Brasil.
Abstract Carcinogenesis is a highly complex process involving both inherited risk factors and environmental ones such as diet, smoking, occupation, and exposure to radiation and chemical agents. Experimental toxi col ogy identifies potentially carcinogenic chemicals and thus makes it possible to introduce regulatory measures aimed at reducing human exposure to them. Carcinogenesis can be viewed as consisting of three distinct sequences: initiation, promotion, and progression. Neoplastic conversion (initiation) occurs when a genetic event (e.g., point mutations, chromosomal rearrangements, insertion or deletion of genes, and geneamplification) results in oncogene activation and/or lack of expression - or inactivation of products - of tumor suppressor genes. Promotion involves clonal expansion of initiated cel Is and requires cell proliferation. Effective strategies for reducing risk of gastric cancer or neoplasias at other sites should include both control of known carcinogens and chemical prevention through rational interventions in the carci nogenic process. The toxicologist's challenge is thus to devise better and less expensive predictive assays and to el uci date the mechanisms underlying chemical carcinogenesi s. Key words Chemical Carcinogenesis; Environment, Stomach Tumours, Toxicology

Resumo A carcinogênese é um processo altamente complexo do qual participam fatores de risco herdados e fatores de risco ambientais, tais como a al imentação, o hábito de fumar, a ocupação, e a exposi ção a radi ação e a agentes químicos. A toxicologi a experimental i dentifica as substâncias quími cas potencial mente carci nogênicas e torna possível medi das regulatórias que objetivam reduzir a exposi ção humana a elas. A carcinogênese pode ser vista como consistindo de três seqüências distintas: a iniciação, a promoção ea progressão. A conversão neoplásica (iniciação) ocorre quando um evento genéti co (mutações, rearranjos cromossômicos, inserções ou deleções de genes e amplificação de genes) resulta em ati vação de oncogenes e/ou em falta de expressão - ou inativação de produtos - de genes supressores de tumores. A promoção envolve a expansão clonal das células “ini ciadas" e exi ge a proliferação celular. Estratégi as efetivas para reduzir os riscos de câncer gástrico e os riscos de neoplasias de outras l ocal izações devem incl uir o controle de carcinógenos conheci dos, assim como a quimioprevenção, por meio de intervenções racionais no processo carcinogênico. Neste senti do, o desafio a ser enfrentado pel o toxicologi sta envolve o desenvol vimento de ensaios predi tivos mel hores e mais baratos ea eluci dação dos mecanismos subjacentes à carcinogênese química.

Palavras-chave Carcinogênese Química, Ambiente, Tumores de Estômago, Toxicologia 


\section{Introdução}

Entende-se por risco a probabilidade de ocorrência de um efeito adverso, durante um certo período de tempo, como resultado de uma determinada exposição. Assim, um fator de risco para o câncer, quando presente, aumenta a probabilidade de ocorrência da doença numa dada população e, quando removido, torna este efeito menos provável.

A prevenção primária do câncer implica ações de Saúde Pública destinadas a reduzir ou eliminar os fatores de risco para a doença. Estas ações voltam-se primariamente para os fatores de risco que são considerados, em princípio, evitáveis, ou seja, aqueles que são extrínsecos ao indivíduo e são, por isso, denominados também de fatores ambientais. No sentido amplo, os fatores ambientais compreendem todas as influências externas que se fazem sentir sobre o indivíduo, como a condição social, a ocupação, os hábitos al imentares, o estilo de vida, a exposi ção a agentes físicos e químicos e assim por diante.

A partir da década de 50 vários estudos mostraram que a incidência de diversos tipos de câncer apresentava acentuadas variações geográficas e temporais em diferentes países, comunidades e grupos de migrantes. Estas constatações foram, em grande parte, acompanhadas da análise de fatores culturais, ocupacionais e estilo de vida e levaram à convicção atual de que em vários tipos de câncer há um importante fator ambiental envolvido (Higginson, 1993). Dois exemplos notáveis neste sentido são o aumento de mortalidade por neoplasias de pulmão e a dramática queda de incidência e mortalidade por câncer de localização gástrica. No início do século, o câncer de pulmão era doença rara; tão rara que a internação de um caso despertava a curiosidade de médicos, residentes e internos, e em uma monografia sobre tumores malignos de pulmão, escrita por I. Adler em 1912, o autor se questionava: "Is it worthwhile to write on such a rare disease?" (Wynder \& Orlandi, 1987). Hoje, na maioria dos países desenvolvidos, o câncer de pulmão desponta como a principal causa de morte por neoplasias entre os homens e tende a ocupar esta posição também entre as mulheres. No caso do câncer de localização pulmonar, há grande acúmulo de evidências epidemiológicas e experimentais apontando o hábito de fumar como o principal fator de risco envolvido. Por outro lado, a incidência de câncer de estômago tem mostrado uma tendência inversa. Relativamente comum no início do século, o câncer gástrico é hoje pouco freqüente nos Estados
Unidos e em países europeus. Entre 1950 e 1980, a mortalidade por câncer de estômago (taxa padronizada para idade por cem mil indivíduos) caiu de 27 para 9 nos Estados Unidos, de 56 para 16 na Suíça, de 109 para 29 na Finlândia, de 41 para 17 na França, de 62 para 35 na Itália, de 46 para 16 na Suécia e de 66 para 27 na Alemanha Ocidental (Howson et al., 1986). Esta queda se deveu, principalmente, à diminuição do tipo intestinal de câncer de localização gástrica e não foi uma vitória de ações de Saúde Pública dirigidas para este fim, mas sim a conseqüência de uma redução não planejada de fatores de risco que, agora, retrospectivamente, os estudos epidemiológicos procuram identificar.

Em contraposição aos fatores ambientais, há o risco intrínseco decorrente da constituição genética, ou o risco herdado pelo indivíduo. O componente de risco genético pode ser muito importante em alguns tipos de câncer e menos importante, ou relativamente pouco importante, em outros. Este risco é visto, em princípio, como não evitável e, portanto, fora do alcance de possíveis ações preventivas. Entretanto, no caso do câncer, como também no de várias outras doenças, a dicotomia que opõe o inato ao adquirido mostra-se frágil. Da mesma forma que o indivíduo não existe fora do meio em que vive, o aparecimento da doença deve ser visto como resultando da relação do sujeito com o ambiente. A predisposição genética só se expressa fenotipicamente a partir da interação do indivíduo com fatores ambientais. Por isso, a vulnerabilidade intrínseca e o agravo extrínseco são dois lados da mesma moeda e é mais útil visualizar a interação dos dois fatores do que abstrair um ou outro componente. Do ponto de vista prático, a identificação dos indivíduos geneticamente mais predispostos a um determinado tipo de câncer permite priorizar ações dirigidas para protegê-los intensivamente de fatores de risco extrínsecos aos quais seriam mais vulneráveis. Um exemplo típico é o das pessoas com xeroderma pigmentosum, que apresentam deficiência de enzimas de reparo por excisão do DNA e que, por isso, são extremamente susceptíveis ao câncer de pele induzido por radiação ultravioleta (Hoffmann, 1991). No futuro, talvez não muito distante, a prevenção do câncer envolverá também a interferência com o fator de risco genético. É possível prever não só a correção da predisposição herdada, mediante algum tipo de terapia genética, como também intervenções que tornem os indivíduos mais resistentes aos fatores de risco ambientais inevitáveis. 


\section{A toxicologia e a prevenção do câncer}

A contribuição mais óbvia da toxicologia para a redução da incidência do câncer em geral se faz por intermédio da identificação dos fatores de risco de natureza química. Na segunda metade deste século, houve um extraordinário desenvolvimento de testes toxicológicos preditivos do potencial carcinogênico de xenobióticos (substâncias químicas não nutrientes estranhas ao organismo).

O termo carcinogênico significa literalmente o que dá origem a neoplasias epiteliais, ou seja, carcinomas. O que dá origem a sarcomas, ou neoplasias de tecido mesenquimal, seria sarcomagênico, e a tumores em geral, oncogênico. Na prática, entretanto, o termo carcinogênico é usado para designar indutores de neoplasias em geral, sentido que mantivemos neste texto. Por outro lado, como salientado por Williams \& Weisburger (1991), a palavra gênico significa dar origem, ou seja, produzir ab initio. Também neste aspecto, usamos o termo em sentido mais amplo, de modo a incluir tanto iniciadores, quanto promotores da carcinogênese.

Os carcinógenos podem ser divididos, a grosso modo, em genotóxicos e epigenéticos ou não genotóxicos. Como veremos adiante neste artigo, no modelo seqüencial de carcinogênese em duas etapas, ou múltiplas etapas (Pitot, 1993), as substâncias mutagênicas são capazes de iniciar a transformação maligna da célula, enquanto um outro grupo de substâncias não genotóxicas, conhecidas como promotores, potencializam o efeito carcinogênico dos iniciadores quando aplicados depois destes. Como os promotores dependem da ação prévia de um iniciador, eles são considerados carcinógenos incompletos. Por outro lado, como os iniciadores genotóxicos podem per selevar ao tumor, eles são considerados carcinógenos completos. Entretanto, as substâncias genotóxicas só são carcinógenos completos, isto é, funcionam também como promotoras, em doses mais elevadas, freqüentemente letais para a célula, aplicadas continuamente. Para a iniciação basta uma única exposição a doses mais baixas, não letais.

A investigação experimental da carcinogenicidade de agentes químicos é feita hoje mediante testes a curto prazo, in vitro e in vivo, cujos end points (mutações gênicas, danos ao DNA e alterações cromossômicas) são relevantes para detecção de substâncias genotóxicas e, portanto, dos carcinógenos genotóxicos (uma revisão atualizada dos testes a curto prazo para detecção de agentes genotóxicos pode ser encontrada em Brusick, 1994); por meio de testes in vivo a médio prazo, cujos end points incluem alterações ou lesões consideradas préneoplásicas, tais como a indução de focos de atividade enzimática modificada em fígado de ratos parcialmente hepatectomizados e, por último, por intermédio dos testes a longo prazo, em que o end point é o aparecimento de neoplasias, o que exige períodos prolongados de tratamento e observação. Os testes preditivos a médio e longo prazo são, em geral, realizados em roedores e detectam os dois tipos de substâncias potencialmente carcinogênicas, as genotóxicas e as não genotóxicas (carcinógenos epigenéticos). O custo aumenta com a duração e complexidade do ensaio, situando-se entre aproximadamente 1.850 dólares para um teste a curto prazo (teste de indução de mutações reversas em Salmonella typhimurium, ou teste de Ames) e cerca de um milhão de dólares para um ensaio a longo prazo realizado em apenas uma espécie de roedor por uma única via de administração (Klaassen \& Eaton, 1991).

Apesar da sofisticação metodológica e da indiscutível utilidade dos estudos experimentais, duas limitações ainda comprometem em maior ou menor grau o valor preditivo dos testes de mutagenicidade/ carcinogenicidade de substâncias químicas (a análise da importância destas limitações na avaliação de risco pode ser encontrada em Paumgartten, 1993).

No caso dos testes in vitro, há a necessidade de extrapolação do resultado obtido para a situação in vivo. Como os sistemas in vitro têm capacidade metabólica limitada e os sistemas extrínsecos de ativação metabólica (mistura S9) não reproduzem necessariamente a biotransformação da substância que ocorre no animal íntegro, resta sempre a possibilidade de um metabólito carcinogênico ser produzido in vivo, mas não nas condições experimentais in vitro. A superação desta limitação metodológica é vital para a substituição de animais por sistemas in vitro, como desejam os defensores do bem-estar dos animais. Por enquanto, ainda é fundamental complementar os testes in vitro com pelo menos um ensaio in vivo na investigação do potencial genotóxico de qualquer xenobiótico.

A outra limitação, mais complexa, é a incerteza subjacente à extrapolação de resultados entre espécies. Sabe-se que há consideráveis diferenças de resposta entre espécies e o que é observado em uma espécie pode não ser extrapolável para outra, tanto em termos quantitativos, quanto qualitativos.

As diferenças interespecíficas de susceptibilidade, pelo menos no que diz respeito aos 
carcinógenos genotóxicos, devem-se em grande parte a dissemelhanças na capacidade metabólica de converter um pró-carcinógeno no metabólito eletrofílico reativo, ou seja, naquele composto que, em última análise, vai causar danos ao DNA (Voisin et al., 1990).

Um exemplo bem conhecido de diferença entre espécies é a resi stência da cobaia ao efeito carcinogênico do 2-acetilaminofluoreno. Isto se deve ao fato de que, neste roedor, as monooxigenases microssomais hepáticas hidroxilam o 2-acetilaminofluoreno predominantemente em um dos carbonos do anel aromático (C-hidroxilação) e não no nitrogênio da cadeia lateral (N-hidroxilação). Como o derivado Chidroxilado (7-hidroxilado) não dá origem a compostos carcinogênicos genotóxicos, ao contrário do que ocorre com os intermediários $\mathrm{N}$-hidroxilados, a cobaia é mais resistente que outros roedores ao efeito carcinogênico do 2acetilaminofluoreno (Williams \& Weisburger, 1991).

Para diminuir a incerteza na avaliação do potencial carcinogênico, seria necessário comparar o metabolismo da substância no homem com a biotransformação do mesmo agente químico na espécie a ser usada no teste. Entretanto, isto implicaria expor o homem à substância em teste, ainda que em doses baixas, antes de se ter chegado a uma conclusão definitiva a respeito da sua carcinogenicidade para a espécie humana.

Em relação ao universo de carcinógenos não genotóxicos, as diferenças entre espécies, entre cepas e, por vezes, entre sexos, são freqüentes e podem resultar de múltiplos fatores. Neste caso, estudos adicionais são freqüentemente realizados para esclarecer o modo de ação do carcinógeno epigenético e avaliar o risco para o homem.

Um exemplo típico são algumas neoplasias renais espécie-específicas e sexo-específicas induzidas por agentes químicos. Os ratos machos são susceptíveis a nefropatias induzidas por substâncias químicas e mediadas por uma proteína, a $\alpha_{2 \mu}$-globulina, sintetizada no fígado e lançada na circulação sistêmica. Esta globulina de baixo peso molecular é captada pelas células do túbulo renal e hidrolisada nos lisossomas. Alguns compostos, como o monoterpeno monocíclico d-limoneno, ligam-se à $\alpha_{2 \mu}$-globulina, o que leva a um acúmulo do complexo substância- $\alpha_{2 \mu}$-globulina que é toxico para as células renais. Os ciclos repetidos de necrose e subseqüente regeneração celular, em decorrência da exposição continuada ao d-limoneno, funcionam então como promotores da oncogênese (Dietrich \& Swenberg, 1991).
Outro exemplo de estudo a longo prazo que exigiu investigações adicionais é o da sacarina. Vários estudos experimentais haviam revelado que a sacarina sódica causava câncer de bexiga em ratos quando administrada por períodos prolongados. A sacarina não é metabolizada e não é genotóxica. Estudos posteriores mostraram que este adoçante artificial adicionado à dieta em altas concentrações ( $\geq 5 \%$ ) produz um aumento dose-relacionado da excreção urinária de compostos indólicos, em conseqüência de alteração do catabolismo de proteínas no cecum. Como os compostos indólicos são reconhecidamente promotores da carcinogênese no nível da bexiga, a ação promotora da sacarina é, aparentemente, indireta. É possível que o sódio, que aumenta o turnover das células da bexiga, também tenha contribuído para o efeito promotor, já que o sal de cálcio da sacarina não induz tumores neste órgão (Williams \& Weisburger, 1991). De qualquer modo, o fato de que há claramente um limiar para este efeito e a constatação de que o nível de dose em que ele ocorre em ratos é extremamente elevado em relação a qualquer uso como adoçante indicam que a sacarina não é um fator de risco relevante para câncer de bexiga no homem.

Os testes toxicológicos preditivos permitem a avaliação do potencial carcinogênico de substâncias a que o homem ainda não foi exposto, isto é, novos produtos, tais como medicamentos, pesticidas, aditivos alimentares, cosméticos e assim por diante. Esta investigação prévia da segurança durante o desenvolvimento de inovações na área químico-farmacêutica se destina a evitar que produtos criados pelo homem venham a constituir novos fatores de risco para o câncer.

A toxicologia experimental permite ainda a avaliação do potencial carcinogênico de substâncias a que o homem já está exposto, ou seja, a identificação dos fatores de risco de natureza química já atuantes no ambiente. Neste terreno, a abordagem experimental é, via de regra, complementar à investigação epidemiológica, corroborando ou desfazendo suspeitas de relações causais. Os estudos epidemiológicos, investigando os fatores de risco para neoplasias diretamente no homem, não são contaminados pelas incertezas inerentes às extrapolações in vivo/ in vitro, ou entre espécies. Entretanto, limitações metodológicas de outro tipo tornam difícil o estabelecimento de relações causaefeito a partir apenas de estudos epidemiológicos. Uma destas limitações é a dificuldade em controlar as inúmeras variáveis intervenientes e em destacar o efeito de um único fator de ris- 
co daquele que resulta da combinação de exposições que ocorre na vida real (poluição do ar, por exemplo). Outra limitação importante é a impossibilidade de obter dados quantitativos precisos sobre a exposição que ocorreu no passado (Swaen, 1988). Esta limitação é particularmente crítica no caso do câncer, uma vez que os eventos iniciadores da neoplasia podem ter ocorrido muitos anos antes da doença ser diagnosticada. A alternativa a esta limitação seriam os longos e caros estudos epidemiológicos prospectivos. Assim, na maioria dos casos em que há dados disponíveis em seres humanos, os estudos experimentais ainda permanecem necessários para complementá-los na identificação dos fatores de risco.

Identificando carcinógenos químicos, a toxicologia possibilita uma estratégia de redução dos riscos de câncer: a ação regulatória para evitar novos fatores de risco e eliminar ou minimizar aqueles a que o homem já está exposto. Evidentemente, há um custo envolvido nestas ações restritivas e existe um eterno conflito entre ambientalistas e a indústria química sobre o custo/ benefício, por exemplo, de determinados limites máximos estabelecidos para poluentes no local de trabalho, ar, solo, água, alimentos e em produtos de uso humano. Esta disputa em torno do custo/ benefício de medidas rigorosas de controle transcende o âmbito estritamente científico e não cabe abordá-la aqui. Entretanto, é discutível se esta estratégia, isoladamente, levará a uma redução substancial da incidência de câncer. Sem dúvida, a eliminação de carcinógenos químicos conhecidos é necessária, mas não são eles os únicos fatores de risco de natureza química atuantes. Há, por exemplo, uma série de processos endógenos que levam à produção de radicais livres de oxigênio capazes de lesar o DNA e levar a mutações oncogênicas. Existem também inúmeras substâncias, como o cloreto de sódio, os ésteres do forbol, e a 2,3,7,8-tetra-cloro-dibenzo-p-dioxina (2,3,7,8-TCDD), que, embora não iniciem a transformação maligna, podem, em determinadas circunstâncias, promover o seu desenvolvimento. Portanto, é provável que não sejam os carcinógenos químicos potentes, detectados pelos testes preditivos, mas sim fatores de risco mais sutis os que contribuem de forma mais significativa para a incidência atual de diversos tipos de neoplasias. Neste contexto, uma estratégia mais eficiente seria a de ações que visassem intervir no mecanismo da carcinogênese, atenuando as influências predisponentes e exacerbando as influências inibitórias do processo. Para intervenções racionais deste tipo, o foco da pesquisa não deve ser a procura de causas isoladas, mas a compreensão dos mecanismos biológicos da carcinogênese.

É neste sentido que se dá a outra contribuição importante da toxicologia experimental para redução dos riscos de câncer: as pesquisas voltadas para a elucidação dos mecanismos da carcinogênese química e para o esclarecimento do modo de ação dos fatores predisponentes.

\section{Os mecanismos da carcinogênese química}

O processo de carcinogênese é altamente complexo, envolve múltiplas etapas e inúmeros xenobióticos, assim como outros fatores ambientais, podem interferir positiva ou negativamente (antimutagênese) em cada um dos passos que levam ao desenvolvimento final da neoplasia. Além disso, os diferentes fatores ambientais podem interagir, aumentando ou diminuindo o efeito de cada um deles quando considerado isoladamente. À luz do conhecimento atual, o desenvolvimento do câncer pode ser visto, esquematicamente, como um processo seqüencial de múltiplas etapas, tal como ilustrado na Figura 1. Operacionalmente, a carcinogênese pode ser descrita como envolvendo as etapas de iniciação, promoção e progressão do tumor.

Iniciação

A etapa de iniciação, como o próprio nome sugere, corresponde ao evento original desencadeador de todo o processo. Este evento é, em última análise, uma alteração estrutural permanente do genoma da célula somática (mutação transmitida às células filhas) que atinge gens fundamentais para regulação e controle do crescimento celular. A mutação pode ter origem em erros no reparo de danos causados ao DNA, e incluem a substituição ou pareamento incorreto de pares de bases levando a mutações pontuais ("point mutations"), adições ou deleções de pequenos segmentos de pares de bases produzindo deslocamentos do quadro de leitura ("frameshift mutations") e transposições que resultam em rearranjos do códon (Cairns, 1981). As mutações relevantes para a iniciação da carcinogênese são aquelas que não matam a célula e que, além disso, levam à ativação e/ ou hiperexpressão de produtos de oncogenes e à inativação ou perda de produtos de genes supressores de tumores (Sugimura, 1992). 
Figura 1

Principais etapas da carcinogênse induzida por agentes químicos genotóxicos. 0 processo de carcinogênese como um todo pode ser visto como uma seqüência de alterações em que as células somáticas progressivamente escapam dos mecanismos que, em condições normais, controlam a sua proliferação. Várias substâncias podem modular a iniciação atenuando-a (e.g. antimutagênese) ou exacerbando-a (e.g. co-carcinogênese), e algumas substâncias “não genotóxicas" (carcinógenos epigenéticos), embora incapazes de iniciar a carcinogênese podem facilitá-la atuando na promoção e progressão (e.g. induzindo a proliferação celular).

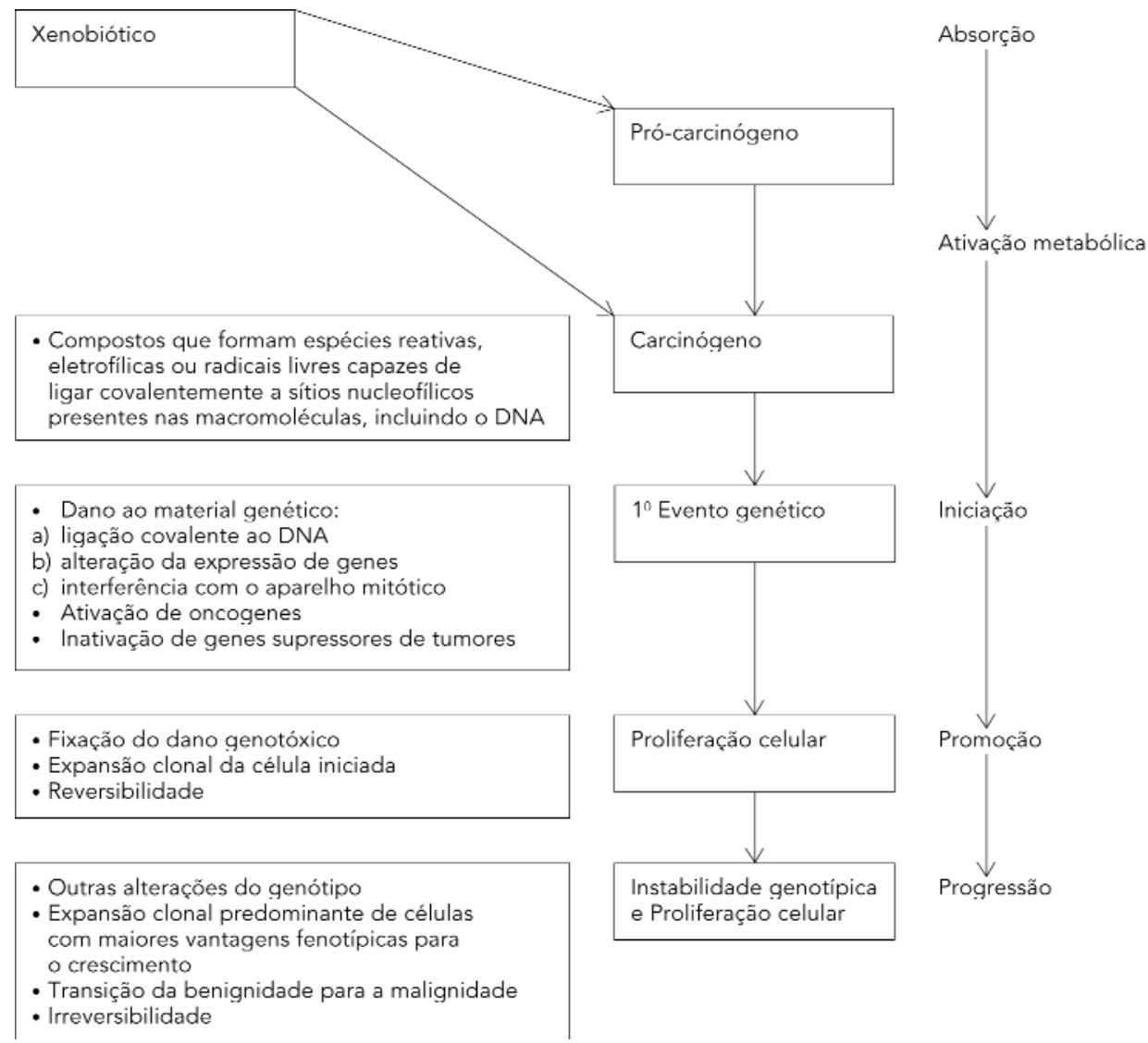

Como salientado por Pitot (1993), a esmagadora maioria das células iniciadas não parece progredir através das etapas subseqüentes do processo de carcinogênese, permanecendo latente no organismo durante toda a vida do indivíduo. Os danos ao DNA, que originam as mutações, são eventos simples, relativamente freqüentes e podem resultar da ação de agentes físicos (radiações ionizantes e não ionizantes), químicos (substâncias genotóxicas existentes na natureza ou introduzidas pelo homem), ou serem produzidos endogenamente (espécies ativas de oxigênio e NO em processos inflamatórios). A iniciação pode resultar também da infecção por alguns vírus oncogênicos (Papovavírus: polyoma, SV40; Adenovírus; Hepadnavírus: hepatite B; Retrovírus: Sarcoma de Rous) cujos genomas são incorporados ao genoma da célula hospedeira. No genoma dos vírus oncogêni- cos, parece haver gens específicos cujos produtos, aparentemente, são os responsáveis primários pela transformação de uma célula normal em célula neoplásica (Pitot, 1993). Além das mutações induzidas por agentes físicos, químicose infecciosos, mutações espontâneas podem surgir a partir de eventos normais, como a depurinação e deaminação do DNA, os danos ao DNA induzidos por radicais livres produzidos pelo metabolismo celular e erros no processo de replicação do DNA durante a divisão celular (Loeb, 1989). Embora a iniciação espontânea seja mais rara do que a induzida, a sua existência é corroborada pela ocorrência de tumores espontâneos em animais de laboratório, cuja incidência varia de acordo com o tecido, a cepa, o sexo e a espécie (Dietrich \& Swenberg, 1991).

Assim, a iniciação parece ser um evento relativamente comum, que pode ocorrer até mes- 
mo espontaneamente, sendo provável que os organismos adultos contenham várias células iniciadas latentes na mai oria de seus órgãos.

\section{Promoção}

Ao contrário da fase de iniciação, em que ocorrem necessariamente alterações no material genético, durante a etapa seguinte de promoção, não há modificações da estrutura do DNA, mas sim mudanças na expressão do genoma. Portanto, de alguma forma, os agentes promotores atuam no processo de transdução de sinais ambientais para o genoma alterado, interferindo assim com a subseqüente expressão do mesmo. Vários agentes promotores têm os seus efeitos mediados por receptores (o acetato de tetradecanoilforbol, TPA, cujo receptor é a proteína kinase c; a 2,3,7,8-tetra-cloro-dibenzo-pdioxina, 2,3,7,8-TCDD, que se liga ao receptor Ah; os estrógenos e andrógenos que se ligam aos receptores estrogênicos e androgênicos, respectivamente, etc.). Nestes casos, o complexo receptor-ligante interage ou se liga de forma não covalente a regiões específicas do DNA, em geral, a montante de determinado gene cuja expressão será por sua vez alterada. Uma outra característica comum a grande parte dos agentes promotores conhecidos, mas não a todos, é a inibição da comunicação intercelular através das "gap junctions". O bloqueio do acoplamento entre células pode levar à expressão fenotípica abrupta de genes anteriormente modificados que haviam sido, até então, mascarados pela existência de uma comunicação intercelular normal (Sugimura, 1992).

Se há uma característica comum a todos os agentes e procedimentos promotores da carcinogênese, esta é a indução de um aumento da proliferação celular. A proliferação celular é necessária para converter o dano ocorrido no DNA em mutação, fixando a alteração genética, e para a expansão clonal da célula iniciada. Além disso, o processo proliferativo e a expansão clonal aumentam a probabilidade de alterações genéticas adicionais nas células iniciadas, isto é, uma segunda mutação, o que leva à etapa subseqüente de progressão do tumor. Assim, substâncias carcinogênicas não genotóxicas, embora não sejam capazes de causar danos ao DNA, estimulam a proliferação celular e, desta forma, contribuem para a fixação de mutações espontâneas e para a expansão clonal das células iniciadas, cuja proliferação acelerada, por sua vez, pode levar a um segundo evento genético e à expansão deste segundo clone, e assim por diante.
Característica comum a todas as substâncias carcinogênicas não genotóxicas testadas experimentalmente é a indução de citotoxicidade e/ ou hiperplasia nos mesmos tecidos dos roedores expostos em que apareceram os tumores. A hiperplasia, ou seja, o crescimento anormal do número de células de um tecido ocorre como resposta compensatória à perda de tecido após lesões (necrose, citotoxicidade, hepatectomia parcial), em decorrência de uma ação mitogênica direta, de um aumento de demanda, ou como resultado de um distúrbio do controle hormonal da atividade do tecido. Observando apenas as características morfológicas das células, às vezes é difícil saber se ainda se trata de uma hiperplasia ou se já se está diante de uma neoplasia. A principal diferença entre as duas situações é que na neoplasia a proliferação excessiva é independente do estímulo, enquanto na hiperplasia as alterações ainda são reversíveis, cessando com a remoção do estímulo.

\section{Progressão}

Se durante a promoção não ocorrem mudanças genéticas e as alterações tissulares (hiperplasia) são reversíveis, a etapa de progressão caracteriza-se pela ocorrência de múltiplas alterações genéticas e pela independência do processo proliferativo da persistência do estímulo. Nesta etapa, a célula torna-se imortalizada e há um aumento progressivo da instabilidade genômica, que se traduz pelo aparecimento freqüente de aberrações cromossômicas nas células neoplásicas. Esta instabilidade pode se dever a mutações que tenham afetado os mecanismos celulares necessários para a fidelidade do processo de replicacão do DNA, a alterações cromossômicas e a hibridização entre diferentes tipos celulares (Williams \& Weisburger, 1991). Portanto, embora o tumor possa resultar da descendência de uma única célula iniciada, há considerável heterogeneidade celular nas neoplasias em virtude desta instabilidade. Tal diversidade celular nos tumores malignos constitui sério problema para o desenvolvimento de métodos quimioterápicos mais eficazes.

\section{Fatores de risco de natureza química para o câncer gástrico}

Como vimos, o extraordinário declínio do câncer gástrico observado neste século na maioria dos países desenvolvidos provavelmente se deveu à redução não intencional de fatores de ris- 
co ambientais. A identificação destes fatores é importante para que se possam programar ações preventivas para diminuir a incidência de tumores de localização gástrica em áreas e países em que ela ainda é alta, como é o caso do Brasil. Neste sentido, a consistência das associações causais apontadas por estudos epidemiológicos deve ser posta à prova por investigações experimentais. Procuraremos analisar aqui al guns fatores químicos possivel mente relevantes para o câncer de estômago, enfatizando os mecanismos pelos quais eles podem contribuir para a gênese de neoplasias de localização gástrica. Em primeiro lugar, como se trata de fatores de risco para o câncer de localização gástrica, os carcinógenos químicos envolvidos devem atuar preferencialmente sobre este órgão. Esta preferência pode ser meramente a conseqüência da via de exposição, através da alimentação, por exemplo, ou ser decorrente de processos mais refinados de organotropismo. O organotropismo de carcinógenos genotóxicos, assim como a especificidade para a espécie ou para determinadas cepas, pode dever-se a diferenças na capacidade de ativação metabólica, ou seja, na presença e/ ou indução de formas distintas de citocromo P450. Outra explicação plausível é a existência de diferenças nos sistemas de reparo do dano ao DNA. Por exemplo, em roedores, o dano causado pela metilnitrosouréia é reparado rapidamente no fígado, a uma velocidade menor nos rins e muito lentamente no cérebro, o que explica o fato deste carcinógeno produzir preferencial mente tumores cerebrais. Outros mecanismos são também possíveis, como a participação da flora na produção in situ do carcinógeno ou a liberação de um pró-carcinógeno, produzido no fígado e transportado como conjugado ao ácido glicurônico, nos intestinos ou bexiga urinária, onde são, então, convertidos no composto eletrofílico (carcinógeno final) que reage com o DNA (Williams \& Weisburger, 1991).

Compostos $\mathrm{N}$-nitrosos e a iniciação do câncer gástrico

Os carcinógenos genotóxicos, em princípio, podem iniciar a conversão de uma célula normal em célula neoplásica em qualquer tecido e, em nível experimental, a especificidade por determinado órgão parece ser mais uma característica dos carcinógenos epigenéticos do que dos genotóxicos. Há, entretanto, casos em que pode haver a distribuição ou a ativação metabólica preferencial do composto genotóxico em determinado órgão ou tecido. Este é o caso, por exemplo, de compostos N- nitrosos que são formados no estômago e podem atuar como iniciadores da conversão neoplásica neste órgão (Kyrtopoulos, 1989). Compostos N-nitrosos, tais como nitrosaminas, nitrosoamidas e nitrosouréias, apresentam potente atividade carcinogênica em animais de laboratório. Derivados nitrosos de al quiluréias e alquilamidas, via de regra, não requerem ativação enzimática específica e liberam, espontaneamente, intermediários reativos em meio aquoso, em pH neutro ou alcalino. Alquilnitrosouréias e substâncias relacionadas (metilnitrosou retana, Nmetil-N-nitro- $\mathrm{N}$-nitrosoguanidina, $\mathrm{N}$-metil- $\mathrm{N}$ nitroso-N`-acetiluréia), nitrosoindóis e diazofenóis, e extratos de peixes e feijões tratados com nitritos, quando administrados por via oral, produzem tumores na porção glandular do estômago de ratos, semelhantes aos que ocorrem com maior freqüência em seres humanos (Williams \& Weisburger, 1991). Os compostos N-nitrosos podem ser formados endogenamente a partir da ingestão de nitritos e nitratos.

Os nitratos têm ampla distribuição na natureza, ocorrem em plantas, são usados na preservação de alimentos e empregados em larga escala como fertilizantes na agricultura, o que pode levar à contaminação de fontes de água potável (Forman, 1989). Além disso, os nitratos são formados endogenamente e estão presentes no sangue. A síntese endógena de nitrato no homem foi estimada em $1 \mathrm{mmol}$ nitrato/ dia (Wagner et al., 1984). Esta síntese é aumentada pela imuno-estimulação, por exemplo, em indivíduos com diarréia intestinal inespecífica e em estados febris. Em ratos, o LPS (endotoxina lipopolissacarídica), a carragenina, a turpentina e as linfokinas estimulam a produção de nitratos e nitritos, o que ocorre, primariamente, nos macrófagos, sendo a L-arginina a fonte do nitrogênio (lyengar et al., 1987).

$\mathrm{Na}$ saliva, o nitrato, assim como outros ânions, aparecem em concentrações maiores do que as encontradas no sangue. Os nitratos podem ser reduzidos a nitritos por microorganismos, o que pode ocorrer em alimentos armazenados à temperatura ambiente (sem refrigeração), bem como por ação de bactérias presentes na cavidade oral, e na bexiga urinária infectada (Bartsch et al., 1989, Calmels et al., 1985, 1987). Por outro lado, os substratos (amidas, uréias, aminas secundárias e aromáticas) para as reações de nitrosação também existem de forma ubíqua nos alimentos ou são formados durante a digestão. Portanto, a formação de compostos N-nitrosos genotóxicos ocorre in situ no estômago. Alterações funcionais do órgão e de componentes da dieta po- 
dem modular este processo. Os estados de hipo- ou acloridria (na gastrite crônica atrófica ou em outras condições que reduzem a secreção ácida) permitem a colonização da mucosa gástrica por bactérias capazes de reduzir nitrato a nitrito, o que aumenta a produção local de nitritos. Entretanto, as reações de nitrosação são dependentes de $\mathrm{pH}$ e a formação de compostos $\mathrm{N}$-nitrosos é ótima na faixa ácida, ou seja, no pH normal do estômago. As reações de nitrosação, por sua vez, podem ser inibidas por neutralização do nitrito com substâncias de ocorrência natural ou sintética presentes nos alimentos, tais como as vitaminas C e E, o sulfamato e alguns antioxidantes, como o butilato de hidroxitolueno, o butilato de hidroxianisole, o ácido gálico e até mesmo aminoácidos e proteínas. Portanto, a importância da contribuição dos nitratos para o desenvolvimento de câncer de localização gástrica parece depender deste complexo balanço de influências facilitadoras e inibitórias na formação in situ de compostos N-nitrosos genotóxicos (Kyrtopoulos, 1989; Wakabayashi et al., 1989).

Recentemente, foi desenvolvido um teste sensível, mas relativamente simples, que permite a quantificação da formação endógena de compostos $\mathrm{N}$-nitrosos em seres humanos. $\mathrm{O}$ teste consiste na administração a indivíduos de um aminoácido, a L-prolina (500 mg), e nitrato (suco de beterraba contendo 260 mg de nitrato), seguida da determinação da quantidade de nitroso-prolina (um composto nitroso não genotóxico e não-carcinogênico) eliminada na urina. A diferença entre a quantidade ingerida de L-prolina e a quantidade de nitrosoprolina excretada na urina nas 24 horas seguintes é um indicador da capacidade endógena diária de nitrosação (Ohshima \& Bartsch, 1981; Bartsch et al., 1989). Alguns estudos clínico-epidemiológicos mostraram que a quantidade de nitrosoprolina excretada na urina e, portanto, a nitrosação in vivo, é maior nos indivíduos de áreas de alto risco para câncer de estômago e esôfago, e também que esta capacidade é acentuadamente reduzida pela ingestão de vitamina C (Bartsch et al., 1989). A despeito de algumas controvérsias, este teste se mostrou sensível e específico para avaliar a exposição a nitritos exógenos e a formação endógena de nitritos, sendo portanto um indicador da exposição individual a compostos $\mathrm{N}$-nitrosos potencialmente carcinogênicos. A utilização do teste de formação in vivo de nitrosoprolina em estudos epidemiológicos pode contribuir para avaliar a real importância da formação de compostos Nnitrosos como fator de risco para o câncer de localização gástrica.
Medicamentos usados no tratamento de úlceras, como a cimetidina e substâncias relacionadas, podem dar origem, no suco gástrico, a um composto $\mathrm{N}$-nitroso semel hante à alquilnitrosouréia. Embora este composto seja genotóxico in vitro, os estudos de carcinogenicidade in vivo foram negativos, sugerindo que o mesmo é eficientemente "detoxificado" no animal íntegro (Williams \& Weisburger, 1991).

\section{Compostos que podem funcionar como promotores do câncer gástrico}

Há vários agentes químicos que induzem a proliferação celular no nível da mucosa gástrica e podem funcionar como promotores de neoplasias deste tecido. A hiperplasia da mucosa pode ser causada por substâncias que causam lesões crônicas, como, por exemplo, o cloreto de sódio em excesso, o butilato de hidroxianisole e o ácido propiônico, ou por compostos que produzem bloqueio funcional (inibidores da secreção gástrica), como os bloqueadores da bomba de próton (omeprazole) ou os antagonistas de receptores $\mathrm{H}_{2}$ da histamina (cimetidina, ranitidina).

\section{Cloreto de sódio em excesso}

Uma série de estudos experimentais realizados principalmente por pesquisadores japoneses indicaram que dietas com altas concentrações de cloreto de sódio podem lesar a mucosa gástrica e torná-la mais susceptível à ação de carcinógenos químicos (Howson et al., 1986). Além de causar gastrite crônica, dietas ricas em $\mathrm{NaCl}$ podem facilitar a absorção de carcinógenos químicos (hidrocarbonetos aromáticos policíclicos), funcionando como promotores do desenvolvimento de tumores em roedores. Estas evidências experimentais não são corroboradas por dados de estudos epidemiológicos que buscaram associações entre câncer de estômago e consumo total de sal per capita. Entretanto, há uma associação clara entre risco de câncer gástrico e cloreto de sódio quando este é consumido em excesso através de alimentos conservados em sal tais como peixes, vegetais, salsichas, presuntos, charque, etc. Nestes alimentos, é provável que outros fatores causais coexistam, tais como compostos $\mathrm{N}$-nitrosos, o que estaria de acordo com a evidência experimental que sugere que o sal em excesso funcionaria como co-carcinógeno (aumentando o efeito de iniciadores quando a exposição é simultânea) ou promotor (potencializando o efeito dos iniciadores quando a exposição é subseqüente). 
Butilato de hidroxianisole e ácido propiônico

O butilato de hidroxianisole (BHA) e o butilato de hidroxitolueno (BHT) são compostos antioxidantes, usados como aditivos de alimentos industrializados. Os antioxidantes de um modo geral, incluindo o $\mathrm{BHA}$ e o $\mathrm{BHT}$, sequestram radicais livres e funcionam como agentes antimutagênicos, ou anticarcinogênicos, em vários sistemas in vitro e in vivo. Apesar de antimutagênicos, o BHT e o BHA inibiram a comunicação intercelular em cultura, o que, como já comentamos, é um efeito característico de substâncias promotoras da carcinogênese. Além disso, I to et al. (1983) demonstraram que a administração crônica de altas doses de BHA ( $2 \%$ na dieta) induzia o aparecimento de hiperplasia e neoplasias no estômago anterior (estômago aglandular) de ratos. Este efeito se deveu à indução de proliferação celular do epitélio escamoso e não apareceu em espécies como o porco, o cão e primatas, que, diferentemente de ratos e camundongos, não apresentam porção agl andular queratinizada no estômago. As lesões em ratos provavel mente se deveram à produção de radicais semiquinona, os quais, em doses muito elevadas de BHA, não seriam prontamente "detoxificados" (Altmann et al., 1986). O BHT também apresentou atividade promotora da carcinogênese in vivo, mas em relação a outros órgãos-alvo, como a bexiga urinária e o fígado. É improvável que o BHA e outros antioxidantes fenólicos relacionados, nas concentrações em que são usados como aditivos, constituam fator de risco para o câncer gástrico, ou de qualquer outra localização, em seres humanos. Entretanto, este exemplo ilustra bem como a mesma substância pode funcionar como anticarcinogênica (bloqueando a iniciação) ou carcinogênica (promovendo o desenvolvimento da neoplasia), dependendo da dose e de outras circunstâncias.

O ácido propiônico, administrado repetidamente na dieta, em concentrações da ordem de $0,4 \%$ a $4 \%$, também produz hiperplasia e neoplasias no estômago anterior do rato (Von Greim, 1985). A proliferação celular excessiva induzida pelo ácido propiônico ocorre após uma fase lag de 28 dias de exposição continuada.

A quase totalidade dos cerca de sessenta agentes químicos que Kroes \& Wester (1986) identificaram como causadores de neoplasias no estômago anterior de roedores diz respeito a substâncias genotóxicas. Entretanto, além do BHA e do ácido propiônico, podem ainda ser encontrados nesta lista outras substâncias não genotóxicas, como a sacarina, o dialil-ftalato e, possivelmente, também, o etilacrilato. Como salientado por Clayson et al. (1991), é possível que neste, como em outros órgãos, a indução e a manutenção de proliferação celular sejam eventos críticos para a promoção da oncogênese.

Inibidores da secreção gástrica

Fármacos que inibem a secreção ácida do estômago, como a cimetidina, a ranitidina e a loxtidina, que bloqueiam o receptor $\mathrm{H}_{2}$ da histamina nas células parietais do estômago, e os bloquedores da $\mathrm{K}^{+}, \mathrm{H}^{+}$-ATPase (bomba de prótons), como o omeprazole, reduzem a acidez gástrica. Este bloqueio funcional desencadeia um mecanismo homeostático para superá-lo e para restabelecer a acidez. A elevação do pH estimula as células $\mathrm{G}$ do piloro a secretar gastrina, produzindo hipergastrinemia. A gastrina estimula as células enterocromafínicas a liberar histamina que, por sua vez, leva as células parietais a produzir a secreção gástrica ácida. Embora a gastrina também estimule diretamente as células parietais, a resposta secretória destas células é potencializada de forma marcante quando os receptores $\mathrm{H}_{2}$ são estimulados concomitantemente (Brunton, 1990). A manutenção do bloqueio farmacológico leva, portanto, à continuidade da estimulação eà hiperplasia das células enterocromafínicas. Carcinomas neuroendócrinos (tumores carcinóides), de aparecimento tardio, foram observados no estômago glandular em ratos tratados cronicamente com loxtidina e omeprazole (Poynter \& Selway, 1991). Além da ação promotora, através da indução de proliferação celular, é possível também que a prolongada acloridria, que favorece a sobrevivência de microorganismos e a colonização da mucosa, facilite a produção de carcinógenos in situ (mediante a redução de nitrato a nitrito). Não há dados sobre tumores carcinóides induzidos por bloqueadores de secreção gástrica no homem. De qualquer modo, como há uma clara associação entre carcinoma gástrico e acloridria no homem e, além disso, como muitos indivíduos tratados para úlcera apresentam também alterações pré-cancerosas no estômago, é recomendável prudência no uso clínico prolongado de medicamentos que causam hipocloridria ou acloridria. 
Conclusões

A carcinogênese é um processo complexo para o qual contribuem tanto fatores predisponentes intrínsecos (predisposição herdada), quanto extrínsecos (fatores de risco ambientais). É possível que, no futuro, por meio da manipulação genética, possa-se alterar a predisposição herdada, mas hoje o alcance das estratégias para reduzir o risco de câncer restringe-se aos fatores de risco ambientais. Neste contexto, a Toxicologia se volta para os fatores de risco de natureza química, identificando carcinógenos através de testes preditivos in vitro e in vivo e desvendando os mecanismos da carcinogênese. Estes fatores incluem substâncias genotóxicas iniciadoras do processo e agentes promotores do desenvolvimento do tumor. A toxicologia preditiva pode contribuir para a prevenção primária do câncer, identificando substâncias potencialmente genotóxicas antes delas serem introduzidas no ambiente e, portanto, antes de ocorrer a exposi ção humana em larga escala, o que subsidia a ação regulatória restritiva das autoridades sanitárias e da área ambiental. Entretanto, o dano genético e a iniciação podem ocorrer também em função de processos endógenos ou ambientais fora do alcance de ações preventivas por intermédio de medidas regulatórias. Neste caso, a prevenção do dano genético iniciador ainda pode ser feita mediante o uso de agentes antimutagênicos, como dietas ricas em vitaminas $\mathrm{C}$ e $\mathrm{E}$ e em outros antioxidantes. Mais complexa é a prevenção dos carcinógenos epigenéticos, que podem atuar, por

\section{Referências}

ALTMANN, H. J.; GRUNOW, W.; MOHR, U.; RICHTERREICHHELM, H. B. \& WESTER, P. W., 1986. Effects of $\mathrm{BHA}$ and related phenols on the forestomach of rats. Food and Chemical Toxi cology, 24:11831188.

BARTSCH, H.; OHSHIMA, H.; PIGNATELLI, B. \& CALMELS, S., 1989. Human exposure to endogenous $\mathrm{N}$-nitroso compounds: quantitative estimates in subjects at high risk for cancer of the oral cavity, oesophagus, stomach and urinary bladder. Cancer Surveys, 8:335-362.

BRUNTON, L. L., 1990. Agents for control of gastric acidity and treatment of peptic ulcers. In: Goodman and Gilman's The Pharmacological Basis of Therapeutics (A. G. Gilman, T. W. Rall, A. S. Nies \& P. Taylor, eds.), 8th ed., pp 897-913, New York/St. Louis/San Francisco: McGraw-Hill Inc. exemplo, no nível da promoção do desenvolvimento do tumor. Neste contexto, a identificação dos carcinógenos não genotóxicos por meio dos demorados e caríssimos ensaios a longo prazo não parece ser a alternativa viável. Além do custo, há a incerteza da extrapolação entre espécies em termos de resultados tanto negativos quanto positivos, bem como a possibilidade de que, na situação real, a combinação de exposições atenue ou exacerbe o efeito. Portanto, mais razoável do que procurar agentes causais específicos é compreender o mecanismo da carcinogênese e o modo pelo qual determinadas substâncias podem promoverou inibir o processo. No caso do câncer gástrico e de neoplasias de outras local izações, a proliferação celular continuada parece ser um evento crítico para a promoção do tumor. Assim, substâncias e circunstâncias que estimulam a proliferação celular, causadas por lesões continuadas ou outros mecanismos, podem funcionar, em princípio, como promotoras. A prevenção neste nível pode ser primária, evitando processos que levem à hiperplasia, e também secundária, já que a hiperplasia e a promoção são reversíveis e cessam se o estímulo for removido. Sendo assim, estratégias eficazes para a redução dos riscos de câncer gástrico e de outras localizações implicam intervenções racionais baseadas no conhecimento dos processos de carcinogênese, à luz do qual a real importância de cada fator ambiental e o resultado das suas interações podem ser devidamente avaliados.
BRUSICK, D., 1994. Genetic Toxicology. In: Principles and Methods of Toxicology (A. W. Hayes, ed.), 3rd ed., pp 545 - 577, New York: Raven Press Ltd.

CAIRNS, J., 1981. The origins of human cancer. Nature, 289:353-357.

CALMELS, S.; OHSHIM A, H.; VINCENT, P.; GOUNOT, A-M. \& BARTSCH, H., 1985. Screening of microorganisms for nitrosation catalysis at $\mathrm{pH} 7$ and kinetic studies on nitrosamine formation from secondary amines by E.coli strains. Carcinogenesis, 6:911-915

CALMELS, S.; OHSHIMA, H.; CRESPI, M.; LECLERC, H.; CATTOEN, C. \& BARTSCH, H., 1987. Nitrosation formation by microorganisms isolated from human gastric juice and urine; biochemical studies on the bacterial catalysed nitrosation. In: The Relevance of $\mathrm{N}$-Nitroso Compounds in Human 
Cancer:Exposures and Mechanisms (H. Bartsch, I. K. O'Neill \& R. Schulte-Hermann, eds.), pp 391395, Lyon: IARC Scientific Publications, n. 84, International Agency for Research on Cancer.

CLAYSON, D. B.; IVERSON, F.; NERA, E. A. \& LOK, E., 1991. Early indicators of potential neoplasia produced in the rat forestomach by non-genotoxic agents: the importance of induced cellular proliferation. Mutation Research, 248:321-331.

DIETRICH, D. R. \& SWENBERG, J. A., 1991. Preneoplasic lesions in rodent kidney induced spontaneously or by non-genotoxic agents: predictive nature and comparison to lesions induced by genotoxic carcinogens. Mutation Research, 248: 239-260.

FORMAN, D., 1989. Are nitrates a significant risk factor in human cancer? Cancer Surveys, 8:443-458.

HIGGINSON, J., 1993. Environmental carcinogenesis. Cancer, 72 (suppl. 3):971-977.

HOFFMANN, G. R., 1991. Genetic toxicology. In: Casarett \& Doull's Toxicology. The Basic Science of Poisons (M. O. Amdur, J. Doull \& C. D. Klaassen, eds.), 4th ed., pp. 201-225, New York/ St. Louis/San Francisco: McGraw-Hill Inc.

HOWSON, C. P.; HIYAMA, T. \&WYNDER, E. L., 1986. The decline in gastric cancer: epidemiology of an unplanned triumph. Epidemiologic Reviews, 8:127.

ITO, N.; FUKUSHIMA, S.; HAGIWARA, A.; SHIBATA, M. \& OGISO, T., 1983. Carcinogenicity of butylated hydroxyanisole in Fischer 344 rats. Journal of the National Cancer Institute, 70:343-352.

IYENGAR, R.; STUEHR, D. J. \& MARLETTA, M. A., 1987. Macrophage synthesis of nitrite, nitrate, and $\mathrm{N}$-nitrosamines: precursors and role of the respiratory burst. Proceedings of the National Academy of Sciences of the USA, 84:6.369-6.373.

KLAASSEN, C. D. \& EATON, D. L., 1991. Principles of toxicology. In: Casarett \& Doull's Toxicology. The Basic Science of Poisons (M. O. Amdur, J. Doull \& C. D. Klaassen, eds.), 4th ed., pp. 12-49, New York/ St Louis/San Francisco: McGraw-Hill Inc.

KROES, R. \& WESTER, P. W., 1986. Forestomach carcinogens: possible mechanisms of action. Food and Chemical Toxicology, 24:1.803-1.809.

KYRTOPOULOS, S. A., 1989. N-nitroso compound formation in human gastric juice. Cancer Surveys, 8:423-442.

LOEB, L. A., 1989. Endogenous carcinogenesis: molecular oncology into the twenty-first century-Presidential Address. Cancer Research, 49:5489-5496.
OHSHIMA, H. \& BARTSCH, H., 1981. Quantitative estimation of endogenous nitrosation in humans by monitoring $\mathrm{N}$-nitrosoproline excreted in the urine. Cancer Research, 41:3.658-3.662.

PAU M GARTTEN, F. J. R., 1993. Risk assessment for chemical substances: the link between Toxicology and Public Health. Cadernos de Saúde Pública, 9:439-447.

PITOT, H. C., 1993. The molecular biology of carcinogenesis. Cancer, 72 (suppl. 3):962-970.

POYNTER, D. \& SELWAY, S. A. M., 1991. Neuroendocrine cell hyperplasia and neuroendocrine carcinoma of the rodent fundic stomach. Mutation Research, 248:303-319.

SU GIMURA, T., 1992. Multistep carcinogenesis: a 1992 perspective. Science, 258:603-607.

SWAEN, G. M. H., 1988. The use of epidemiological data in risk assessment. Regulatory Toxicology and Pharmacology, 8:422-430.

VOISIN, E. M.; RUTHSATZ, M.; COLLINS, J. M. \& HOYLE, P. C., 1990. Extrapolation of animal toxicity to humans: interspecies comparisons in drug development. Regulatory Toxicology and Pharmacology, 12:107-116.

VON GREIM, W., 1985. Tumorgene Wirkung von Propionsäure an der Vormagenschleimhaut von Ratten. Bundesgesundheitsblatt, 28:322-327.

WAGNER, D. A.; YOUNG, V. R.; TANNENBAUM, S. R.; SCHULTZ, D. S. \& DEEN, W. M., 1984. Mammalian nitrate biochemistry:metabolism and endogenous synthesis. In: N-Nitroso Compounds: Occurrence and Biological Effects and Rel evance to Human Cancer (I. K. O'Neill \& R. C. Von Borstel, eds.), pp 247-253, Lyon: IARC Scientific Publications, n. 57, International Agency for Research on Cancer.

WAKABAYASHI, K.; NAGAO, M. \& SUGIMURA, T., 1989. Mutagens and carcinogens produced by the reaction of environmental aromatic compounds with nitrite. Cancer Surveys, 8:385-399.

WILLIAMS, G. M. \& WEISBURGER, J. H., 1991. Chemical carcinogens. In: Casarett \& Doull's Toxicology. The Basic Science of Poisons (M. O. Amdur, J. Doull \& C. D. Klaassen, eds.), 4th ed., pp. 125-200, New York/St Louis/San Francisco: McGraw-Hill Inc.

WYNDER, E. L. \& ORLANDI, M. A., 1987. Primary prevention of tobacco-related cancer. In: Cancer Risks. Strategies for Elimination (P. Banasch, ed.), pp. 114-132, Berlin/Heidelberg: Spriger-Verlag. 